\title{
Joint modulations of Taiwan rainfall by tropical cyclone, northeast monsoon, and intraseasonal oscillation in October
}

\author{
Tzu-Ling Lai ${ }^{1}$, Jau-Ming Chen ${ }^{1, *}$, Chung-Hsiung Sui ${ }^{2}$, Mei-Yun Tsai ${ }^{1}$, Ching-Feng Shih $^{3}$, and \\ Wei-Teh $\mathrm{Li}^{4}$ \\ ${ }^{1}$ Department of Maritime Information and Technology, National Kaohsiung University of Science and Technology, \\ Kaohsiung City, Taiwan \\ ${ }^{2}$ Department of Atmospheric Science, National Taiwan University, Taipei City, Taiwan \\ ${ }^{3}$ Marine Meteorology Center, Central Weather Bureau, Taipei City, Taiwan \\ ${ }^{4}$ Department of Oceanography, National Sun Yat-sen University, Kaohsiung City, Taiwan
}

\section{Article history: \\ Received 14 June 2021 \\ Revised 31 August 2021 \\ Accepted 6 September 2021}

Keywords:

Tropical cyclone, Northeast monsoon, ISO, Taiwan rainfall, October

Citation:

Lai, T.-L., J.-M. Chen, C.-H. Sui, M.-Y. Tsai, C.-F. Shih, and W.-T. Li, 2021: Joint modulations of Taiwan rainfall by tropical cyclone, northeast monsoon, and intraseasonal oscillation in October. Terr. Atmos. Ocean. Sci., 32, 1163-1179, doi: 10.3319/ TAO.2021.09.06.01

\begin{abstract}
Taiwan experiences a distinct seasonal transition in fall from the summer to winter monsoon. In October, the northeasterly monsoon impinges on Taiwan's Central Mountain Range producing heavy rainfall in eastern Taiwan. In addition to monsoonal influences, tropical cyclones (TCs) move along the Western Pacific warm pool to the south and southwest of Taiwan over the $115^{\circ}-122^{\circ} \mathrm{E}$ region. These are found to influence rainfall over eastern Taiwan by enhancing the meridional pressure gradient with the resultant northeasterly flows moving toward Taiwan. During TC warning periods, this meridional pressure gradient on maximum rainfall day over northeastern Taiwan (Ilan) is strong for TCs with a northern track (north of $19^{\circ} \mathrm{N}$ ) and weak for those with a southern track (south of $19^{\circ} \mathrm{N}$ ). For TCs with a northern track, intensified northeasterly flows merge with cyclonic flows in the northern sector of a TC-related low centered in the South China Sea (SCS). Flow confluences and moisture flux convergence occur over Taiwan causing strong rainfall over eastern Taiwan, but immediately to the west of Taiwan in relation to weak rainfall over eastern Taiwan. For TCs with a southern track, moisture flux convergence shifts southward over the SCS, leading to very weak rainfall over Taiwan. Rainfall variability in different interaction types is mainly determined by the 3-10-day transient mode. The major effect of 30-60-day intraseasonal oscillation (ISO) mode is to provide favorable conditions due to large-scale cyclonic anomalies across the SCS and tropical western North Pacific. These conditions steer westward TC movement over oceans to the south and southwest of Taiwan.
\end{abstract}

\section{INTRODUCTION}

Climate over East Asia and the western North Pacific (WNP) is affected by large-scale monsoonal circulations. The major circulation features include the Pacific subtropical high (PSH) and monsoon trough (MT) during the warm season and the Siberian high during the cold season. The PSH and MT displace northward during summer, stay at the northernmost location in August, and shift southward in September and October (Lander 1996). The MT is a region of strong vorticity and convections. These conditions facili-

\footnotetext{
* Corresponding author

E-mail:cjming@nkust.edu.tw
}

tate tropical cyclone (TC) activity (Chen et al. 2006; Wu et al. 2012). The MT and PSH undergo evident variability on intraseasonal and interannual time scales modulating TC activity accordingly (Harr and Elsberry 1991; Chan 2000; Lu 2001; Lu and Dong 2001; Wang and Chan 2002; Chen et al. 2009; Tu and Chen 2019). In terms of intraseasonal oscillation (ISO) modulations on TC genesis, TCs tend to form under favorable enhanced-convection conditions within a cyclonic ISO anomaly ( $\mathrm{Li}$ et al. 2012; Klotzbach 2014). During a convective ISO phase, increased TC genesis occurs in the eastern sector of the tropical WNP south of $15^{\circ} \mathrm{N}$ (Kim et al. 2008). The TC genesis rate (from tropical disturbances into a named TC) in the WNP is also enhanced 
during a convective 30-60-day phase with a major increase occurring over the southeastern WNP (Chen et al. 2018a). In terms of TC track, TCs in the WNP tend to move westward/northwestward during convective ISO phases and recurve northward during non-convective phases ( $\mathrm{Li}$ and Zhou 2013). The WNP TCs may move westward toward the South China Sea (SCS) from being steered by anomalous easterly flows either in the southern periphery of an anomalous 30-60-day anomalous anticyclone northeast of the SCS or between a 30-60-day circulation pair consisting of a northern anomalous anticyclone and a southern anomalous cyclone (Chen et al. 2017, 2019). The former anomalous anticyclone is accompanied by a westward-intensified $\mathrm{PSH}$, while the latter circulation pair is associated with a southeastward intensification of the MT. For TCs heading from the tropical WNP toward the northwestern North Pacific, they first form in the southeastern/eastern sectors of a northwest-southeasterly extending 30-60-day cyclonic anomaly and later move northwestward along this cyclonic anomaly toward its central region over the northwestern North Pacific (Chen et al. 2018b). Taiwan is a subtropical island affected by the PSH and MT in summer and by the Siberian high in fall and winter. TCs and monsoon-related circulations appear as two important factors determining local rainfall variability in Taiwan (Chen et al. 2005, 2010b, 2013; Chen and Chen 2011).

For TC activity in Taiwan, 1911 - 2019 statistics compiled by the Central Weather Bureau of Taiwan (https:// www.cwb.gov.tw/V8/C/K/Encyclopedia/typhoon/index. html) reveal dominant TC activity in Taiwan from July to
September with $79.1 \%$ of TCs occurring in this season. TCs also affect Taiwan in June and October at $7 \%$ and $8.3 \%$ of the annual TC counts, respectively. TC-induced rainfall is critical to Taiwan's water supply. Island-wide on average, TC-related rainfall accounts for $12 \%$ of total rainfall during May to June (Chen et al. 2010a), 47.5\% during July to September (Chen et al. 2010b), and 27\% during October (Chen et al. 2013). Locally, TC-related rainfall can be as much as $60 \%$ of total rainfall in eastern Taiwan from July to October (Kubota and Wang 2009). Su et al. (2012) reported that about $70 \%$ of Taiwan's extreme rainfall events were caused by torrential rains brought by TCs during July to October. TC-related heavy rainfall events in Taiwan have tended to increase over recent decades in accordance with reduced TC speed following a weakening in steering flows over the WNP (Tu and Chou 2013).

TC activity in Taiwan from June to October related to different monsoonal circulations. To illustrate this difference, climatological (1960 - 2016) means of 10-m winds for August, September, and October compiled from the National Centers for Environmental Prediction-National Center for Atmospheric Research (NCEP-NCAR) reanalysis data are shown in Fig. 1. In August (Fig. 1a), Taiwan is located within a MT extending southeastward from southeastern China toward the tropical WNP and is influenced by southwest monsoonal flows from the SCS that are the southern component of the MT. In September (Fig. 1b), the MT shifts southward with a more zonal extension from the SCS toward the tropical WNP. Southwesterly flows remain in the southern section of the SCS, while northeasterly flows enter
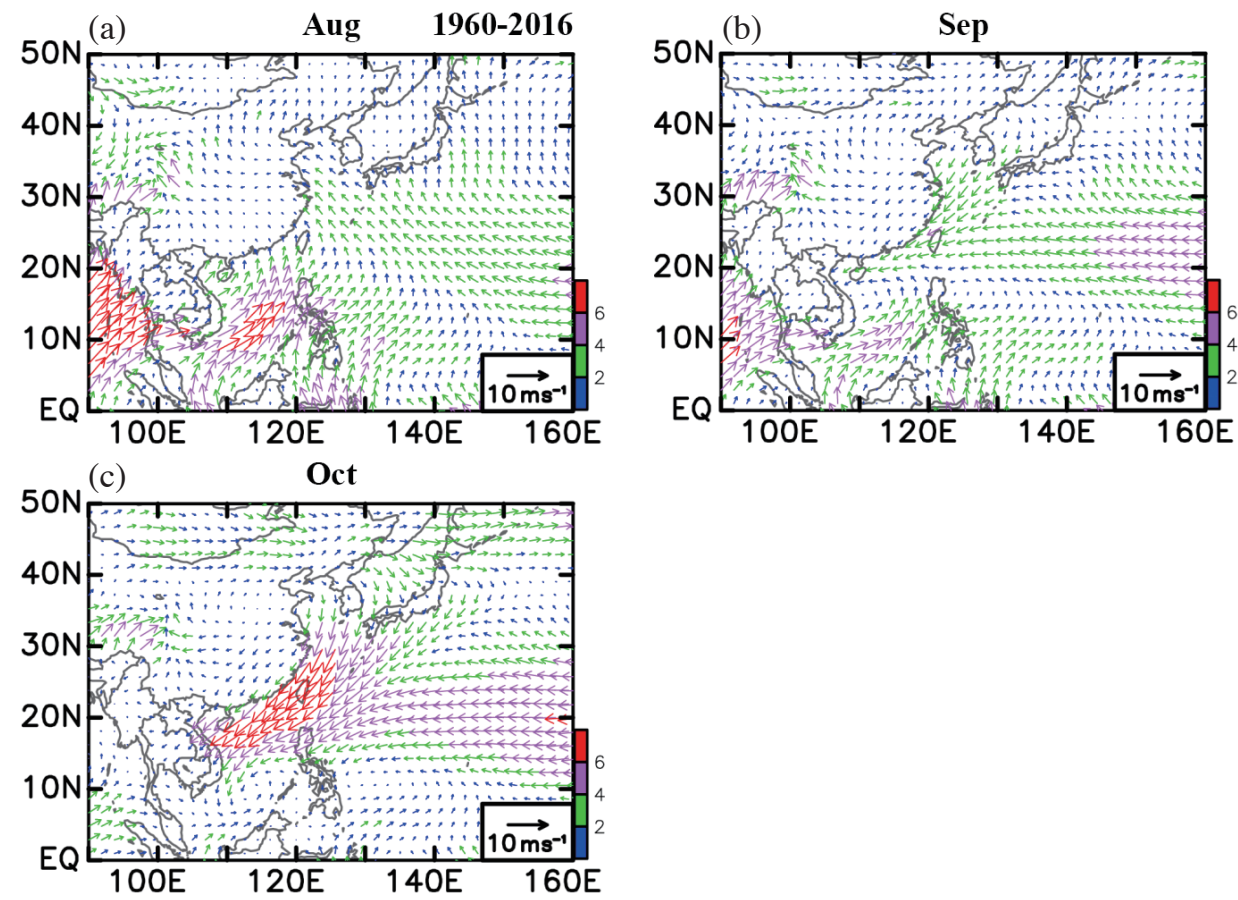

Fig. 1. The climatological (1960 - 2016) means of 10-m winds for (a) August, (b) September, and (c) October. 
the northern sector of the MT to affect Taiwan. In October (Fig. 1c), the MT displaces further southward to leave room for the entrance of strong northeasterly flows across Taiwan toward the SCS in company with an intensification of the Siberian high. The above evolutionary features show how Taiwan is affected by the southwest monsoon in August and the northeast monsoon in October with the transition occurring during September.

There is a peculiar feature to TC rainfall in Taiwan. During summer, TCs delivering rainfall to Taiwan follow two particular track types (Chen and Shih 2012; Chen et al. 2013). These two track types may interact with ISO circulations and the southwest monsoon resulting in extremely heavy rainfall events. In terms of the first track type, the 3060-day ISO propagates northwestward guiding TCs northwestward from the WNP toward northern Taiwan (Chen et al. 2013). During landfall and the ensuing several days, a cyclonic ISO anomaly with its center to the north of Taiwan induces anomalous westerly flows on its southern side to enhance seasonal southwest monsoonal flows from the SCS onto Taiwan. Strong moisture convergence caused by persistent moisture supply yields prolonged heavy rainfall along western Taiwan. For the second track type, a meridional circulation pair of ISO anomalies propagates northward from the tropical WNP (Chen and Shih 2012). This pair crosses Taiwan guiding TCs northward to make landfall or approach northern Taiwan. The low-pressure system pertaining to a TC around northern Taiwan enhances the meridional pressure gradient toward the north leading to an intensification of southwesterly monsoonal flows. Further, during such periods, Taiwan is sandwiched by the cyclonic ISO anomaly to the north and anticyclonic anomaly to the south. This pair further strengthens southwest monsoonal flows toward western Taiwan via anomalous westerly flows moving between them. The combined effects of TCs and ISO anomalies lead to extensive heavy rainfall over Taiwan while TCs are around northern Taiwan or after their departures. One extreme rainfall event caused by the interactions of a TC, ISO anomaly, and southwesterly monsoonal flows occurred in August 2009. Typhoon Morakot moved northwestward through northern Taiwan and interacted with strong southwest monsoonal flows intensified by a slow northwestward-propagating cyclonic ISO anomaly, causing $2900 \mathrm{~mm}$ of rainfall within three days in the mountainous region over southern Taiwan (Hong et al. 2010; Huang et al. 2011).

The above studies clearly illustrate the effect of interactions between TCs, ISOs, and southwest monsoonal flows inducing significant rainfall events over Taiwan. Taiwan's TC activity not only occurs during summer's southwest monsoon season, but also in the northeast monsoon season during October. However, interactions between TCs, ISOs, and northeast monsoonal flows during October and their effects on local rainfall in Taiwan have not thus far been comprehensive studied. The main purpose of this study is to investigate rainfall variability in Taiwan during October modulated by the joint effects of TCs, northeast monsoonal flows, and ISOs. To achieve this goal, the following questions are pursued:

-What are the major relationships between TC track features and major rainfall variability types during October rainfall events in Taiwan?

- For each rainfall variability type, how do interactions between TCs and northeasterly monsoonal flows affect local rainfall in Taiwan?

- What is the relative role of ISO anomalies in the modulation of local rainfall over Taiwan for each variability type?

TC activity during the northeast monsoon season has attracted less attention than its counterpart during the southeast monsoon season. Results of this study should advance our understanding of joint effects among TCs, ISOs, and the northeast monsoon in the WNP. Hopefully, predictions of $\mathrm{TC}$ activity and local rainfall in Taiwan during the northeast monsoon season can be improved.

\section{DATA}

Three datasets are analyzed in this study. The first dataset includes daily rainfall records from 10 major meteorological stations of the Central Weather Bureau (CWB), Taiwan. They are used to analyze rainfall variability features in Taiwan. The geographic distributions of these stations with respect to topography in Taiwan are shown in Fig. 2. The second dataset is the daily means of the National Centers for Environmental Prediction-National Center for Atmospheric Research (NCEP-NCAR) reanalysis data (Kalnay et al. 1996). Variables of 10-m winds, 850-hPa streamfunction, and winds and specific humidity at different vertical levels are employed to illustrate large-scale processes modulating local rainfall variability in Taiwan. The third dataset is 6-hourly best track data in the WNP compiled by the Joint Typhoon Warning Center (JTWC). These data are used to select TC cases affecting Taiwan during October, focusing on their track features plus position and time corresponding to maximum rainfall in Taiwan. To have a comprehensive climatic study, the analysis period in this study spans from 1960 to 2016.

\section{CLIMATOLOGICAL PATTERNS OF OCTOBER RAINFALL IN TAIWAN}

Rainfall features over Taiwan during October are depicted by the climatological (1960 - 2016) means of October monthly rainfall over 10 major stations in Taiwan. As shown in Fig. 3, October rainfall has a value from 125 to $407 \mathrm{~mm}$ on the windward side of northeast monsoonal flows in the regions to the north, east, and south of the Central Mountain Ranges (CMRs) from Taipei across the east coast 


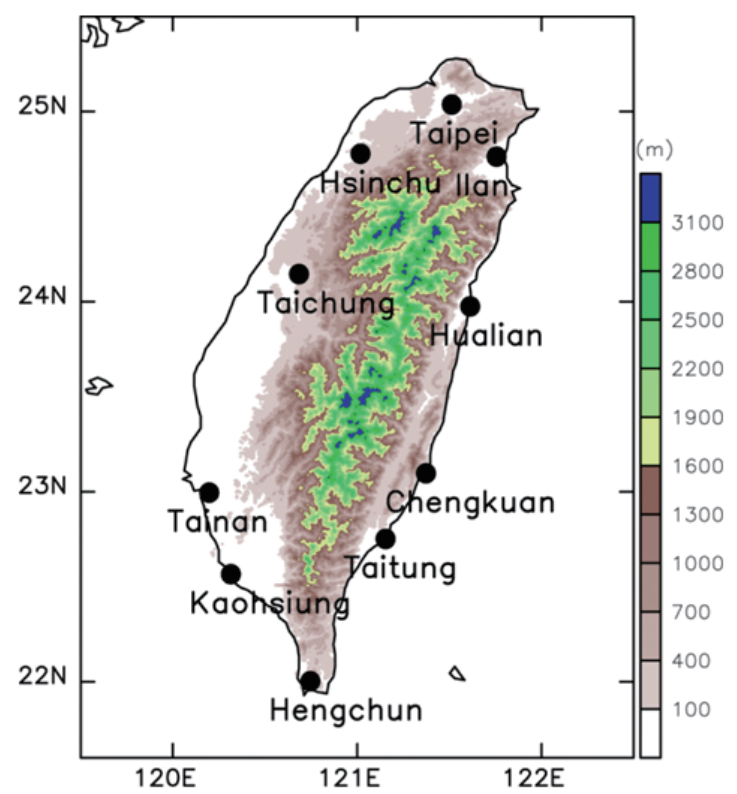

Fig. 2. Distribution of 10 major meteorological stations over the topography of Taiwan.

to Hengchun. On the lee side of northeast monsoonal flows over the west coast, rainfall decreases to a value less than $100 \mathrm{~mm}$. Maximum rainfall occurs over the northeast coast at Ilan $(407 \mathrm{~mm})$. The climatological (1960 - 2016) monthly rainfall at Ilan has an annual mean of $217 \mathrm{~mm}$ and a standard deviation (SD) of $99 \mathrm{~mm}$ (not shown). Since it is in the frontier region directly encountering northeast monsoonal flows, rainfall at Ilan is much larger in the northeast monsoon season (September to December) than the southwest monsoon season (May to August). Deviating from the annul mean by $1.9 \mathrm{SDs}$, October rainfall at Ilan $(407 \mathrm{~mm})$ reaches the maximum value of its annual cycle. This rainfall is also greater than rainfall at other stations over eastern Taiwan. Therefore, it is legitimate to use October rainfall at Ilan for studying the impacts of northeast monsoon-related features on local rainfall over eastern Taiwan.

\section{TC TRACK FEATURES ASSOCIATED WITH RAINFALL VARIABILITY IN TAIWAN}

During October, Taiwan's rainfall can be affected by remote interactions between TCs and the northeast monsoon. These interactions generally occur when a TC tracks across the ocean to Taiwan's south and southwest (Chen and $\mathrm{Wu}$ 2016; Lin and $\mathrm{Wu} 2021$ ). The outer flows of such a TC are too distant to affect eastern Taiwan directly. However, the appearance of a TC in the south acts as a lowpressure center enhancing the meridional pressure gradient between this TC and the high-pressure northeast monsoon to the north. The enhanced meridional pressure gradient in turn effectively intensifies northeast monsoonal flows

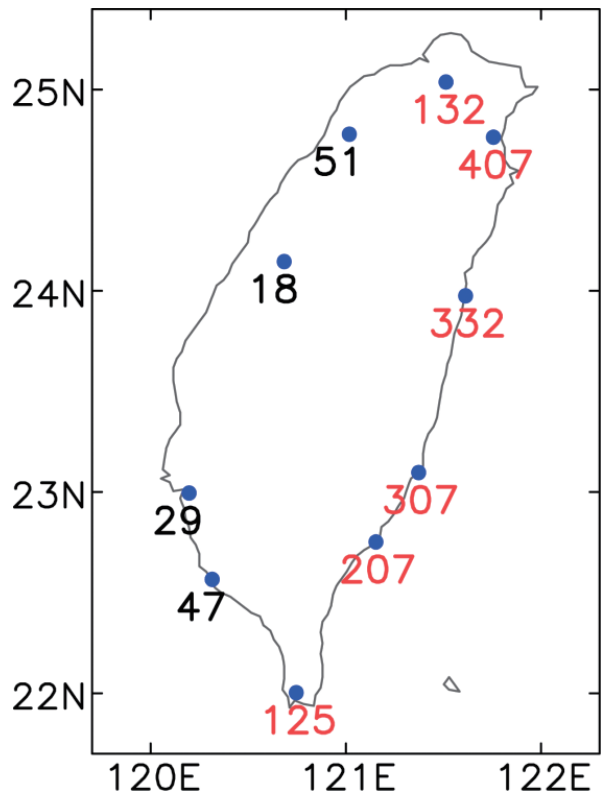

Fig. 3. The climatological means of monthly rainfall of October for 10 major stations in Taiwan (unit: $\mathrm{mm}$ ).

with a southward movement transporting moisture toward Taiwan. This remote interaction between TCs to the southwest and south of Taiwan and the northeast monsoon to the northeast of Taiwan may result in the evident rainfall over eastern Taiwan. This is a peculiar TC-related remote rainfall feature during the cool season.

According to the Typhoon Data Bank compiled by the CWB (https://rdc28.cwb.gov.tw/TDB/public/warning typhoon list/), 18 TCs formed in the WNP and later crossed the ocean to Taiwan's south during October from 1960 to 2016. These TCs are listed in Table 1. Relevant information includes year, name, and the period for which TC warning were issued by the CWB. Also included are the size and intensity of TCs represented by respective radii of $28-\mathrm{kt}$ sustained wind speeds $\left(\mathrm{R}_{28}\right.$; equivalent to Beaufort force- 7 level) and maximum wind speeds (Vmax) when TCs are closest to Taiwan. The effects of TC-northeast monsoon interactions on Taiwan's rainfall are depicted by date and maximum daily rainfall at Ilan when a TC associated with a TC warning appears in regions south and southwest of Taiwan over the $115^{\circ}-122^{\circ} \mathrm{E}$ region. The warning period for TC Elaine (1968) is from 27 September to 1 October. This TC is considered an October TC for our analysis although its maximum daily rainfall occurred on 30 September.

The selected 18 TCs are categorized into different variability types based upon their track features and maximum daily rainfall at Ilan. TCs with maximum daily rainfall greater (smaller) than $100 \mathrm{~mm}$ are sorted as strong (weak) rainfall types. At 0600 UTC of maximum rainfall days at Ilan, six out of seven TCs of the strong rainfall type are located to the north of $19^{\circ} \mathrm{N}$, while eight out of 
Table 1. Information for each TC in the four TC types: year, name, radius of 28-kt sustained wind speed $\left(\mathrm{R}_{28}\right)$, maximum wind speed near Taiwan (Vmax), the warning period, and date and amount of maximum daily rainfall at Ilan.

\begin{tabular}{|c|c|c|c|c|c|c|c|}
\hline & \multirow{2}{*}{ year } & \multirow{2}{*}{ TC } & \multirow{2}{*}{$\begin{array}{l}\mathbf{R}_{28} \text { radius } \\
\quad(\mathbf{k m})\end{array}$} & \multirow{2}{*}{$\begin{array}{c}\text { Vmax near Taiwan } \\
\qquad\left(\mathrm{m} \mathrm{s}^{-1}\right)\end{array}$} & \multirow{2}{*}{ TC warning period } & \multicolumn{2}{|c|}{ Ilan } \\
\hline & & & & & & date with max daily rainfall & Max daily rainfall (mm) \\
\hline \multirow{6}{*}{ Strong-N } & 1968 & Elaine & 400 & 60 & September 27 - October 1 & September 30 & 365 \\
\hline & 1973 & Nora & 350 & 63 & October $7-10$ & October 9 & 160 \\
\hline & 1987 & Lynn & 400 & 53 & October $22-27$ & October 24 & 129 \\
\hline & 1998 & Babs & 250 & 35 & October 25 - 27 & October 25 & 383 \\
\hline & 2009 & Parma & 250 & 43 & October $3-6$ & October 5 & 199 \\
\hline & 2010 & Megi & 250 & 48 & October $21-23$ & October 21 & 357 \\
\hline mean & & & 317 & 50.3 & & & 265 \\
\hline \multirow{3}{*}{ Weak-N } & 1962 & Dinah & 350 & 51 & October $1-3$ & October 3 & 20 \\
\hline & 1975 & Elsie & 200 & 70 & October $11-13$ & October 13 & 9 \\
\hline & 2016 & Aere & 120 & 18 & October $5-6$ & October 6 & 41 \\
\hline mean & & & 223 & 46.3 & & & 23 \\
\hline Strong-S & 1967 & Carla & 400 & 60 & October $15-18$ & October 17 & 233 \\
\hline \multirow{8}{*}{ Weak-S } & 1964 & Dot & 150 & 35 & October $9-10$ & October 10 & 87 \\
\hline & 1973 & Patsy & 300 & 65 & October $11-12$ & October 12 & 1 \\
\hline & 1974 & Bess & 300 & 38 & October $10-12$ & October 12 & 51 \\
\hline & 1974 & Della & 150 & 40 & October $23-24$ & October 24 & 41 \\
\hline & 1982 & Nancy & 200 & 58 & October $14-15$ & October 15 & 7 \\
\hline & 1988 & Pat & 200 & 38 & October 19 - 21 & October 21 & 24 \\
\hline & 1989 & Angela & 250 & 67 & October 5 - 7 & October 7 & 3 \\
\hline & 1999 & Dan & 250 & 38 & October 4 - 9 & October 5 & 42 \\
\hline mean & & & 225 & 47.4 & & & 32 \\
\hline
\end{tabular}

eleven TCs of the weak rainfall type situate to the south of $19^{\circ} \mathrm{N}$. Therefore, a TC situating to the north (south) of $19^{\circ} \mathrm{N}$ during the maximum rainfall day at Ilan is sorted as the northern (southern) track type. Based on these two criteria, the $18 \mathrm{TCs}$ are separated into four types: strong rainfall with northern tracks (Strong-N), weak rainfall with northern tracks (Weak-N), strong rainfall with southern tracks (Strong-S), and weak rainfall with southern tracks (Weak$\mathrm{S})$. There are six Strong-N cases, three Weak-N cases, one Strong-S case, and eight Weak-S cases. Major variability types appear as Strong-N and Weak-S with Weak-N being a minor variability type. There is only one Strong-S type TC. It has been excluded from analysis due to a lack of representation. Comparisons between the Strong-N and Weak-S types indicate that TCs with a northern track tend to induce more rainfall over eastern Taiwan than TCs with a southern track. Comparisons between the Strong-N and Weak-N types delineate major differences in dynamic and moisture processes modulating rainfall over eastern Taiwan caused by the two TC groups although they have a similar northern track. The above comparisons help provide more insight into TC-northeast monsoon interactions. This insight may lead to improvements in TC rainfall prediction for Taiwan.
TC tracks for these four variability types are given in Fig. 4. TC positions at 0600 UTC on Ilan's maximum rainfall days are marked with TC symbols.

Table 1 shows that maximum daily rainfall means for Ilan are much larger for the Strong-N type $(265 \mathrm{~mm})$ than Weak-N (23 mm) and Weak-S (32 mm) types. Regarding TC size, three TCs (Dinah, Pasty, Bess) in the Weak-N type have a $R_{28}$ value of $300-350 \mathrm{~km}$ which is larger than three TCs (Babs, Parma, Megi) of the Strong-N type with a value of $250 \mathrm{~km}$. In terms of TC intensity, the averaged Vmax values for TCs of the Strong-N, Weak-N, and Weak-S types are 50.3, 46.3, and $47.4 \mathrm{~m} \mathrm{~s}^{-1}$, respectively. They are relatively close to each other. Two TCs of the Weak-N type (Dinah, Elsie) and three TCs of the Weak-S type (Patsy, Nancy, Angela) have their Vmax values larger than the averaged values of the Strong-N type. The above results indicate that size and intensity of a TC do not fully determine local rainfall variability in eastern Taiwan.

Composite rainfall patterns in Taiwan on maximum rainfall day at Ilan (day 0) for three TC types are shown in Fig. 5. For all TC types, rainfall on the west coast is much smaller than that on the east coast. For Strong-N type TCs (Fig. 5a), rainfall greater than $150 \mathrm{~mm}$ occurs over northern 
and eastern coastal regions. For Weak-N type TCs (Fig. 5b), rainfall at Ilan is only $23 \mathrm{~mm}$, while greater rainfall at 85 $115 \mathrm{~mm}$ occurs farther south in central regions of the east coast. For Weak-S type TCs (Fig. 5c), rainfall further decreases to $32-75 \mathrm{~mm}$ in the east coast. Rainfall over eastern Taiwan is greater under Strong-N type TCs than Weak-N and Weak-S types. Overall, rainfall variability at Ilan shows a uniform variability feature with other stations over eastern Taiwan, being strong in the Strong-N type and weak in the Weak-N and Weak-S types. This indicates that rainfall at Ilan can adequately reflect rainfall variability features over eastern Taiwan in response to TCs moving to the south and southwest of Taiwan during October. The existence of the Weak- $\mathrm{N}$ type reveals that TC-related rainfall variability over eastern Taiwan is not a simple one-to-one relation with more rainfall for a northern-track TC and less rainfall for a southern-track TC. Weak rainfall over eastern Taiwan in the Weak-N and Weak-S types is induced by TCs of different track in association with different moisture processes. This will be demonstrated later. These two TC types should be considered independent from each other.

TCs analyzed in this study are located to the south and southwest of Taiwan. Their own outer flows are too distanct to reach Ilan directly. As mentioned previously, rainfall at

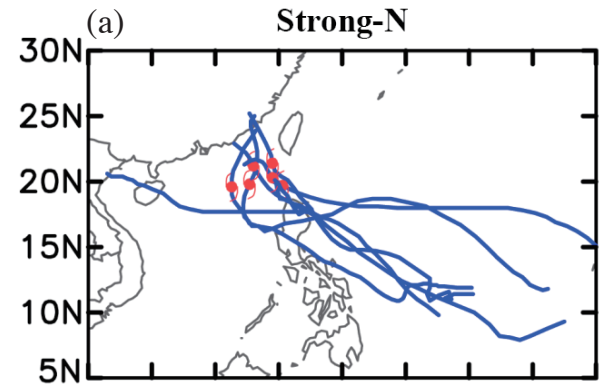

(b)

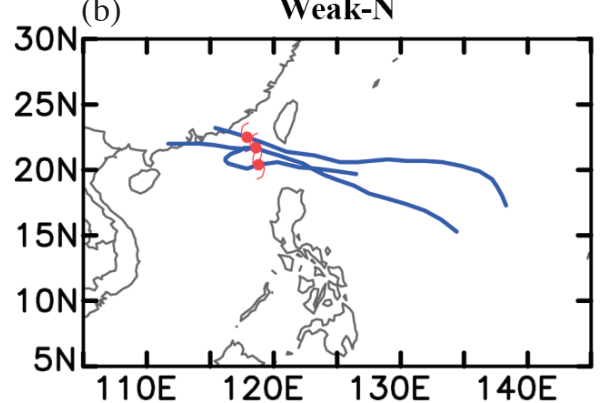

(c)

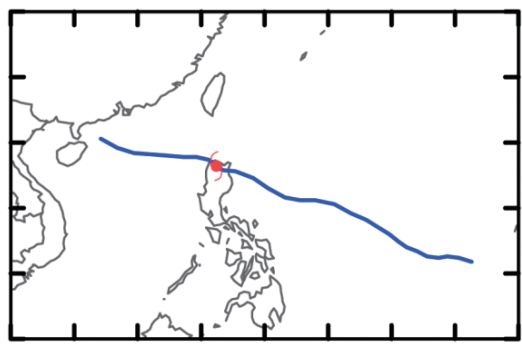

(d)

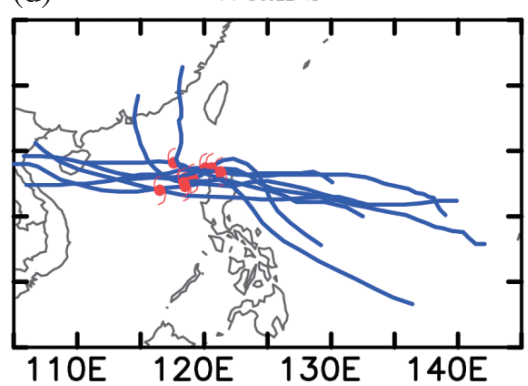

Fig. 4. Tracks of TCs for the four TC types categorized in Table 1: (a) strong rainfall with northern tracks (Strong-N), (b) weak rainfall with northern tracks (Weak-N), (c) strong rainfall with southern tracks (Strong-S), and (d) weak rainfall with southern tracks (Weak-S). TC locations at 0600 UTC of the day with the maximum daily rainfall at Ilan are marked by TC symbols.
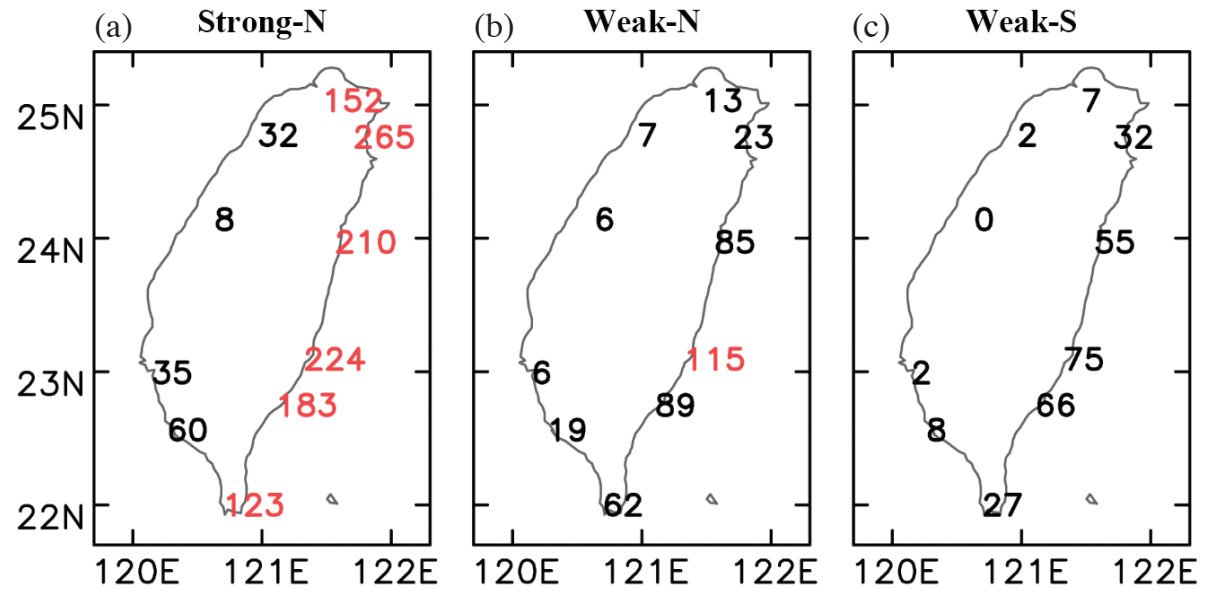

Fig. 5. Composite rainfall means in Taiwan on the day with the maximum daily rainfall at Ilan for the (a) Strong-N type, (b) Weak-N type, and (c) Weak-S type (unit: $\mathrm{mm}$ ). 
Ilan can be increased by transport of more moisture toward the windward side of eastern Taiwan in company with intensified northeasterly flows. These intensified flows are associated with an enhanced meridional pressure gradient following the appearance of a TC to Taiwan's south and southwest. Through these processes, there may exist some remote interactions between TCs and northeast monsoonal flows to induce evident rainfall over eastern Taiwan during October. How these remote interactions occur and affect local rainfall over eastern Taiwan is worthy of detailed examination.

\section{LARGE-SCALE MODULATING PROCESSES}

To examine interactions between TC-related circulation features and northeasterly monsoonal flows around Taiwan, composite means of real-time $850-\mathrm{hPa}$ streamfunction (S850) and 10-m wind (V10) on day 0 for the three TC types are shown in Fig. 6. Hereafter, composite patterns significant at the 0.1 level of the Student- $t$ test are shaded. Composite S850 patterns exhibit a common feature; that is, a zonal extending high north of Taiwan and an isolated low southwest of Taiwan centered in the SCS. This circulation pair results in a meridional pressure gradient guiding flows from the northern high southward toward Taiwan. For Strong-N (Fig. 6a) and Weak-N (Fig. 6b) type TCs, Taiwan is beneath the northeastern boundary of the southern low. The meridional pressure gradient is larger in the former than the latter. For Weak-S type TCs (Fig. 6c), Taiwan is located between the northern high and southern low, leading to a weaker meridional pressure gradient than those for Strong-N and Weak-N types. Regarding V10 patterns for Strong-N type TCs (Fig. 6d), strong northeasterly flows move southward to merge with southeasterly flows of the southern low in regions around Taiwan. For Weak$\mathrm{N}$ type TCs (Fig. 6e), both the northern high and southern
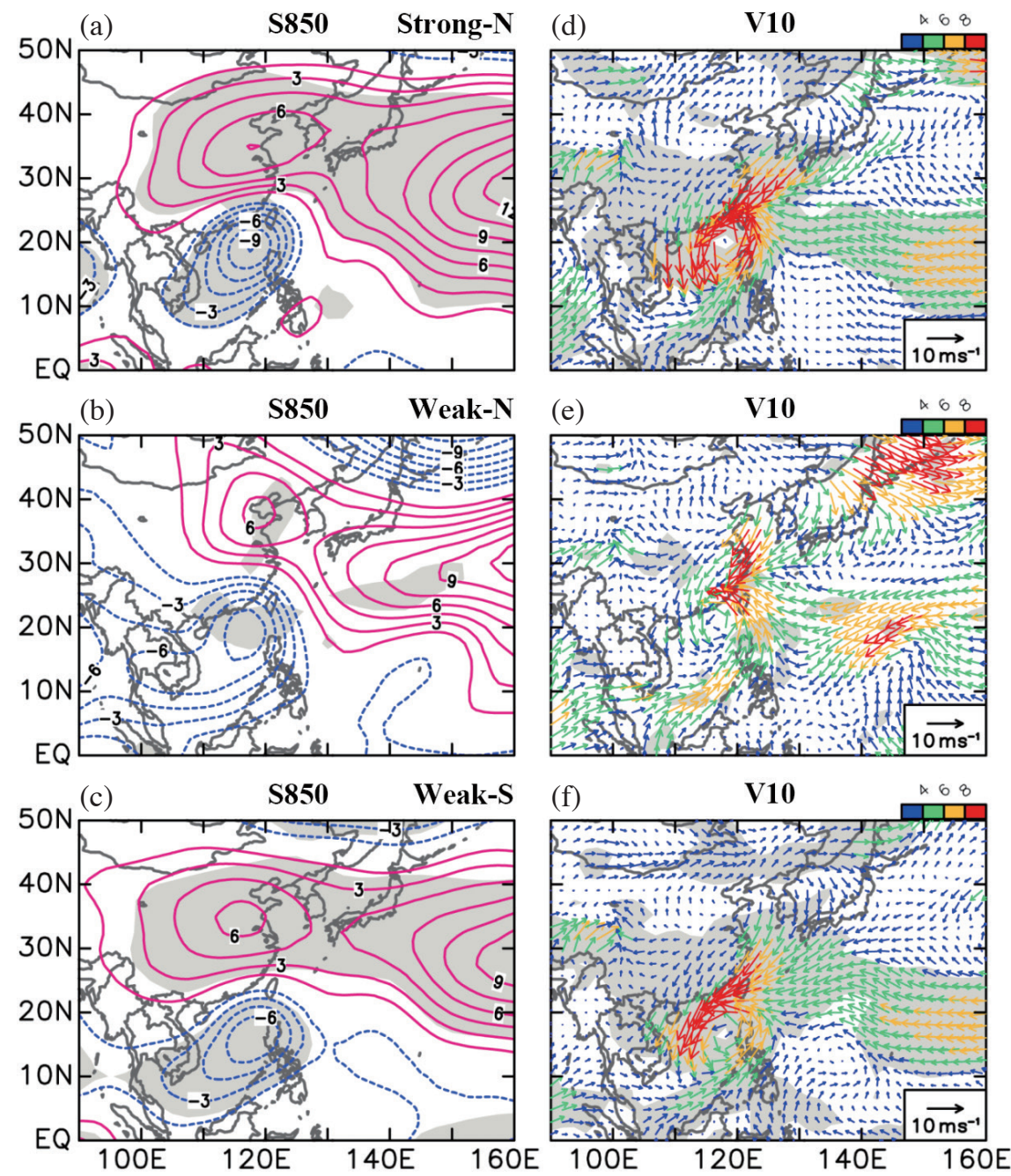

Fig. 6. Composite means of real-time 850-hPa streamfunction (S850)/10-m winds (V10) on the day with the maximum daily rainfall at Ilan associated with TCs selected in the (a)/(d) Strong-N type, (b)/(e) Weak-N type, and (c)/(f) Weak-S type. Composite patterns significant at the 0.1 level of the Student- $t$ test are shaded. Contour intervals of S850 are $1.5 \times 10^{6} \mathrm{~m}^{2} \mathrm{~s}^{-1}$. 
low are similarly located as for Strong-N type TCs, but with weaker intensity. Northeasterly flows shift westward merging with southeasterly flows over China's southeast coast. For Weak-S type TCs (Fig. 6f), northeasterly flows pass over Taiwan merging with southeasterly flows of the southern low in the northern SCS to Taiwan's southwest.

Flow confluences for these three TC types occur over different regions which should result in different variability features for moisture convergence and rainfall over Taiwan. To illustrate associated moisture processes, divergence of vertically-integrated moisture flux $\left(\nabla \cdot \mathbf{V}_{\mathrm{Q}}\right)$ is computed, where $\mathbf{V}_{\mathrm{Q}}=\int_{p}^{p_{0}} \mathbf{V} q d p, \mathbf{V}$ is the horizontal wind, $q$ is the specific humidity, and the integration is from a given level ( $p=$ $500 \mathrm{hPa})$ to the reference level $\left(p_{0}=1000 \mathrm{hPa}\right)$. Composite means of real-time $\nabla \cdot V_{\mathrm{Q}}$ on day 0 of the three TC types are shown in Fig. 7. In these TC types, the major center of moisture flux convergence (negative pattern) is overly- ing Taiwan for the Strong-N type (Fig. 7a), to the west of Taiwan for the Weak-N type (Fig. 7b), and to the south of Taiwan for the Weak-S type (Fig. 7c). These major centers spatially correspond well with the major flow confluences between northeasterly flows and the southern low for different TC types. Intensity of $\nabla \cdot \mathbf{V}_{\mathrm{Q}}$ is strongest for Strong-N type TCs and weakest for the Weak-S type. This matches well local rainfall intensity over eastern Taiwan. To quantitatively compare these features, averages of local rainfall in six stations on the windward side of northeasterly flows across northern, eastern, and southern Taiwan (Taipei, Ilan, Hualian, Chengkuan, Taitung, Hengchun) and $\nabla \cdot \mathbf{V}_{\mathrm{Q}}$ over the Taiwan region $\left(120^{\circ}-122.5^{\circ} \mathrm{E}, 22.5^{\circ}-25^{\circ} \mathrm{N}\right)$ on day 0 are listed in Table 2. Also compared are the averaged TC positions on day 0 for each TC type. The averaged TC position is north of $20^{\circ} \mathrm{N}$ for the Strong-N $\left(118.6^{\circ} \mathrm{E}, 20.3^{\circ} \mathrm{N}\right)$ and Weak- $\mathrm{N}\left(118.4^{\circ} \mathrm{E}, 21.5^{\circ} \mathrm{N}\right)$ types, and in a more southern
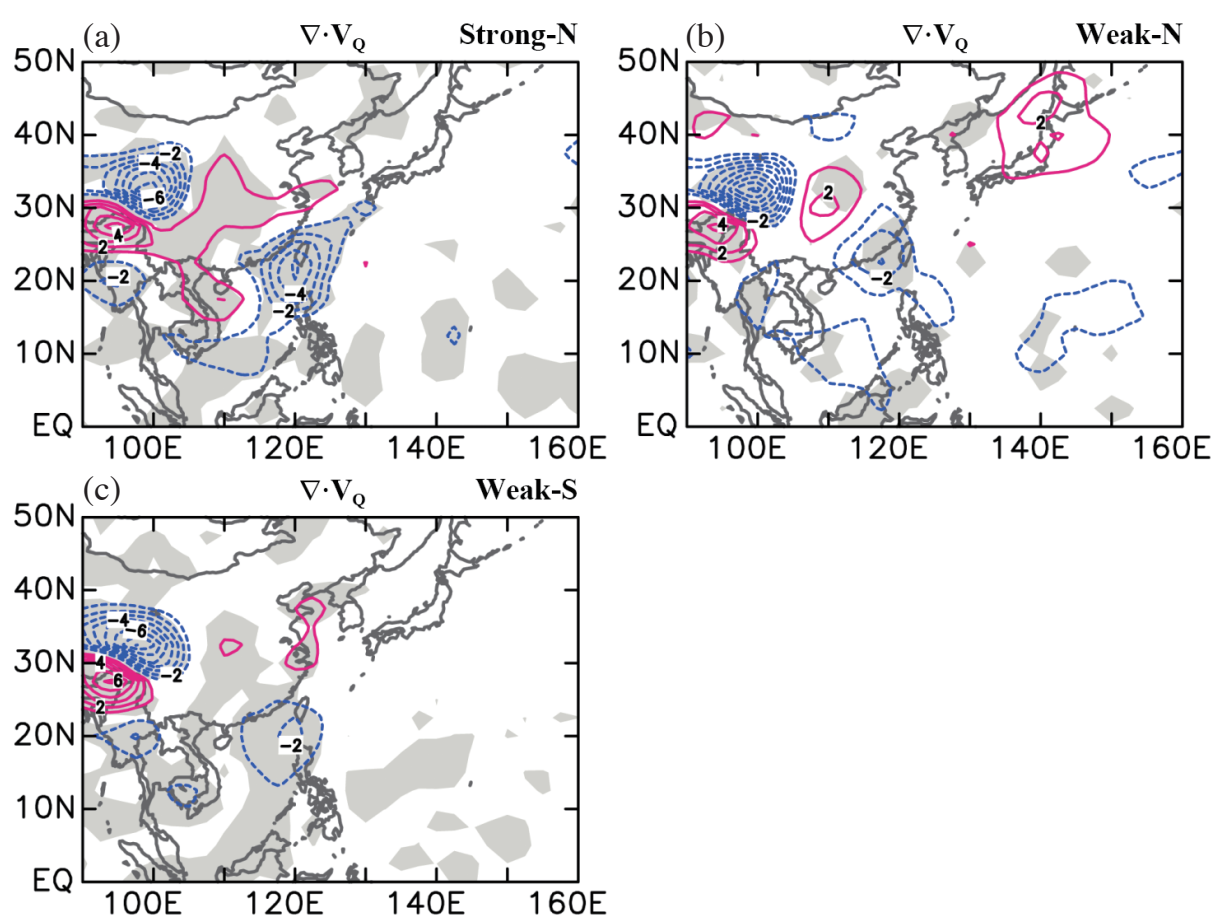

Fig. 7. As in Fig. 6, except for composite means of real-time divergence of moisture flux $\left(\nabla \cdot \mathbf{V}_{\mathrm{Q}}\right)$ for the (a) Strong-N type, (b) Weak-N type, and (c) Weak-S type. Contour intervals are $1 \times 10^{-4} \mathrm{~kg} \mathrm{~m}^{-1} \mathrm{~s}^{-1}$. Composite means significant at the 0.1 level of the Student- $t$ test are shaded.

Table 2. Composite means of TC position, rainfall over six Taiwan stations, and areal means of $\nabla \cdot \mathbf{V}_{\mathrm{Q}}$ over Taiwan $\left(120^{\circ}-122.5^{\circ} \mathrm{E}, 22.5^{\circ}-25^{\circ} \mathrm{N}\right)$ for real time, 3-10-day, and 30-60-day modes on day 0 for the major TC types.

\begin{tabular}{c|c|c|c|c|c}
\hline \multirow{2}{*}{ TC type } & \multirow{2}{*}{ Mean TC position } & \multirow{2}{*}{$\mathbf{P}(\mathbf{m m})$} & \multicolumn{3}{|c}{$\nabla \cdot \mathbf{V}_{\mathbf{Q}}\left(\mathbf{1 0}^{-\mathbf{5}} \mathbf{~ k g ~ \mathbf { ~ m } ^ { - 1 } \mathbf { ~ s } ^ { - 1 } )}\right.$} \\
\cline { 4 - 6 } & & & Real time & $\mathbf{3}-\mathbf{1 0}$ day mode & $\mathbf{3 0}$ - 60 day mode \\
\hline Strong-N & $118.6^{\circ} \mathrm{E}, 20.3^{\circ} \mathrm{N}$ & 232 & -39.0 & -18.9 & -6.6 \\
Weak-N & $118.4^{\circ} \mathrm{E}, 21.5^{\circ} \mathrm{N}$ & 65 & -14.8 & -5.8 & -2.4 \\
Weak-S & $119.0^{\circ} \mathrm{E}, 18.1^{\circ} \mathrm{N}$ & 44 & -11.4 & -5.6 & -1.1 \\
\hline
\end{tabular}


position for Weak-S type TCs $\left(119.0^{\circ} \mathrm{E}, 18.1^{\circ} \mathrm{N}\right)$. Rainfall and moisture flux convergence over Taiwan are strongest for Strong-N type TCs with values of $232 \mathrm{~mm}$ and $-39 \times$ $10^{-5} \mathrm{~kg} \mathrm{~m}^{-1} \mathrm{~s}^{-1}$, respectively. These values are followed by respective $65 \mathrm{~mm}$ and $-14.8 \times 10^{-5} \mathrm{~kg} \mathrm{~m}^{-1} \mathrm{~s}^{-1}$ for the Weak-N type. The weakest values are for the Weak-S type at $44 \mathrm{~mm}$ and $-11.4 \times 10^{-5} \mathrm{~kg} \mathrm{~m}^{-1} \mathrm{~s}^{-1}$, respectively. These results indicate that stronger moisture flux convergence over Taiwan induces stronger local rainfall.

TCs of both Strong-N and Weak-N types induce a cyclonic circulation to the southwest of Taiwan. The associated northeasterly flows exhibit a confluent zone across Taiwan toward the central region of the cyclonic circulation in the Strong-N type (Fig. 6d), leading to moisture flux convergence centering in the ocean southwest of Taiwan and extending northeastward across Taiwan toward Japan (Fig. 7a). For the Weak-N type, the confluent zone associated with the northeasterly flows displaces to the north of Taiwan and merges with the cyclonic circulation in the region west of Taiwan (Fig. 6e), yielding a weak moisture flux convergence to the west of Taiwan (Fig. 7b). For the Weak-S type, the northeasterly flows pass through Taiwan to merge with the cyclonic circulation in the region south of Taiwan (Fig. 6f). Weak moisture flux convergence has its center to the south of Taiwan. The above analyses demon- strate that the center of major moisture flux convergence is mainly determined by flow confluence between the northeasterly flow and TC-related cyclonic circulation.

\section{ASSOCIATIONS WITH MERIDIONAL PRESSURE GRADIENT AND NORTHEASTERLY FLOW FEATURES}

Our analyses delineate that TCs with a track south and southwest of Taiwan can interact with northeasterly flows to modulate local rainfall on Taiwan via changes in the meridional pressure gradient and flow confluence. Chen and $\mathrm{Wu}$ (2016) demonstrated that this type of TC may have its related cyclonic circulations encounter northeasterly flows and cause frontogenesis off the northeast coast of Taiwan. This frontal system enhances the entrance of northeasterly flows toward eastern Taiwan under which strong vertical motion is triggered to induce evident rainfall. Lin and $\mathrm{Wu}$ (2021) pointed out that the direction of impinging northeasterly flows may affect interactions between inland northeasterly flows and Taiwan's topography, leading to different rainfall variability over eastern Taiwan. Associations between rainfall variability over eastern Taiwan and the meridional pressure gradient, frontogenesis, and impinging northeasterly flows are analyzed and summarized in Table 3 .

Table 3. The meridional pressure gradient, frontogenesis, and speed and direction of northeasterly flows for each TC analyzed in this study.

\begin{tabular}{|c|c|c|c|c|c|c|c|c|}
\hline & \multirow{2}{*}{ year } & \multirow{2}{*}{ TC } & \multicolumn{3}{|c|}{ SLP (hPa) } & \multirow{2}{*}{ Front near Taiwan } & \multicolumn{2}{|c|}{$\operatorname{V10}\left(\mathrm{m} \mathrm{s}^{-1}\right)$} \\
\hline & & & NE point (A) & SW/S region (B) & $\nabla \mathbf{P}(\mathbf{A}-\mathbf{B})$ & & speed & direction \\
\hline \multirow{6}{*}{ Strong-N } & 1968 & Elaine & 1009 & 1002 & 7 & Yes & 9.8 & $48^{\circ}$ \\
\hline & 1973 & Nora & 1006 & 999 & 7 & No & 8.9 & $72^{\circ}$ \\
\hline & 1987 & Lynn & 1010 & 1001 & 9 & Yes & 9.9 & $39^{\circ}$ \\
\hline & 1998 & Babs & 1011 & 1004 & 7 & Yes & 8.3 & $80^{\circ}$ \\
\hline & 2009 & Parma & 1008 & 1003 & 5 & Yes & 10.2 & $42^{\circ}$ \\
\hline & 2010 & Megi & 1006 & 999 & 7 & Yes & 10.7 & $39^{\circ}$ \\
\hline mean & & & & & 7 & & 9.6 & $53^{\circ}$ \\
\hline \multirow{3}{*}{ Weak-N } & 1962 & Dinah & 1005 & 1000 & 5 & No & 5.9 & $113^{\circ}$ \\
\hline & 1975 & Elsie & 1009 & 1004 & 5 & Yes & 6.3 & $54^{\circ}$ \\
\hline & 2016 & Aere & 1011 & 1006 & 5 & No & 7.1 & $83^{\circ}$ \\
\hline mean & & & & & 5 & & 6.4 & $83^{\circ}$ \\
\hline \multirow{8}{*}{ Weak-S } & 1964 & Dot & 1013 & 1008 & 5 & No & 9.5 & $75^{\circ}$ \\
\hline & 1973 & Patsy & 1010 & 1008 & 2 & No & 3.3 & $67^{\circ}$ \\
\hline & 1974 & Bess & 1005 & 1000 & 5 & Yes & 10.2 & $45^{\circ}$ \\
\hline & 1974 & Della & 1013 & 1009 & 4 & No & 9.2 & $60^{\circ}$ \\
\hline & 1982 & Nancy & 1012 & 1009 & 3 & No & 9.1 & $39^{\circ}$ \\
\hline & 1988 & Pat & 1013 & 1009 & 4 & No & 7.2 & $50^{\circ}$ \\
\hline & 1989 & Angela & 1014 & 1010 & 4 & No & 10.1 & $27^{\circ}$ \\
\hline & 1999 & Dan & 1013 & 1008 & 5 & No & 6.1 & $58^{\circ}$ \\
\hline mean & & & & & 4 & & 8.1 & $53^{\circ}$ \\
\hline
\end{tabular}


The meridional pressure gradient is measured from a sea level pressure (SLP) difference between a northeastern (NE) point right off the coast of Ilan $\left(122.5^{\circ} \mathrm{E}, 25^{\circ} \mathrm{N}\right)$ and the major TC-gathering region in a southwestern (SE) region $\left(117.5^{\circ}-120^{\circ} \mathrm{E}, 20^{\circ}-22.5^{\circ} \mathrm{N}\right)$ for the Strong-N and Weak-N types, or in a southern (S) region $\left(117.5^{\circ}-120^{\circ} \mathrm{E}\right.$, $17.5^{\circ}-20^{\circ} \mathrm{N}$ ) for the Weak-S type. Their SLP difference (NE minus SW or S) ranges in $5-9 \mathrm{hPa}$ for the Strong-N type, $5 \mathrm{hPa}$ for the Weak-N type, and $2-5 \mathrm{hPa}$ for the Weak$\mathrm{S}$ type. Their averaged pressure gradients are 7,5 , and 4 $\mathrm{hPa}$, respectively. The meridional pressure gradient tends to be largest in the Strong-N type, followed by the Weak-N type, and weakest in the Weak-S type. Rainfall over eastern Taiwan remotely affected by a TC to Taiwan's south and southwest appears to be enhanced in association with an enhanced meridional pressure gradient between the TC and the high-pressure northeast monsoon to Taiwan's northeast.

For associations with frontogenesis, daily V10 patterns on maximum rainfall days at Ilan are employed to detect the occurrence and location of the frontal system (not shown). As shown in Table 3, five out of six Strong-N type TCs are associated with a frontal system immediately off the northeast coast of Taiwan. On the other hand, only one out of three TCs in the Weak-N type and one out of eight TCs in the Weak-S type are accompanied by a frontal system near Taiwan. As revealed by Strong-N type TCs, the coexistence of a TC to Taiwan's south and southwest and a frontal system near Taiwan's northeast coast tends to enhance rainfall over eastern Taiwan. Frontogenesis near Taiwan appears as a favorable condition for enhanced rainfall over eastern Taiwan resulting from remote interactions between a TC in the SCS and the northeast monsoon to Taiwan's northeast.

Associated features of northeasterly flows are analyzed from 10-m winds on maximum rainfall days at Ilan. They are the speed and direction of the northeasterly flows from a domain $\left(122.5^{\circ}-127.5^{\circ} \mathrm{E}, 25^{\circ}-30^{\circ} \mathrm{N}\right)$ for the frontal system to approach Taiwan. As shown by Table 3, the averaged wind speed is stronger in the Strong-N $\left(9.6 \mathrm{~m} \mathrm{~s}^{-1}\right)$ and Weak-S $\left(8.1 \mathrm{~m} \mathrm{~s}^{-1}\right)$ types than the Weak-N $\left(6.4 \mathrm{~m} \mathrm{~s}^{-1}\right)$ type. For wind direction, the averaged inflow angle is $53^{\circ}$ (approximating northeasterly flows) for both Strong-N and Weak-S types, but $83^{\circ} \mathrm{N}$ (approximating easterly flows) for the Weak-N type. In general, easterly flows may better interact with the north-southerly distributed CMRs to enhance topographic lifting, providing favorable conditions for heavy rainfall. However, the larger value for averaged wind direction in the Weak-N type $\left(83^{\circ} \mathrm{N}\right)$ than the Strong-N type $\left(53^{\circ} \mathrm{N}\right)$ does not correspond to stronger rainfall. Moreover, both the Strong-N and Weak-S types have the same averaged wind direction $\left(53^{\circ} \mathrm{N}\right)$ but distinct rainfall variability. These results indicate that inflow angle of the northeasterly flow is not the only factor fully determining rainfall variability over eastern Taiwan under TC-northeast monsoon interactions for all TC cases analyzed in this study.
The above analyses reveal that enhanced rainfall over eastern Taiwan associated with TC-northeast monsoon interactions during October is primarily modulated by flow confluence and moisture flux convergence near Taiwan. Enhanced meridional pressure gradient and frontogenesis near Taiwan provide favorable conditions for evident rainfall over eastern Taiwan.

\section{THE RELATIVE ROLE OF ISO ON RAINFALL VARIABILITY FOR DIFFERENT TC TYPES}

Confluences of northeasterly flows and the cyclonic flows of the TC-related southern low in the SCS result in various degrees of moisture convergence and rainfall over Taiwan for different TC types. What is the relative role of a low-frequency ISO in modulating rainfall over Taiwan compared to the high-frequency TC-related transient mode? To examine this issue, ISO and TC-related transient modes are represented by 30-60-day and 3-10-day components, respectively. These two modes are extracted by Lanczos bandpass filter (Duchon 1979) using daily data from September to November of each year. Another ISO component, i.e., the 10-30-day mode, is considered to partially mix with TC signal (Aiyyer et al. 2012) and thus excluded from the analysis of ISO modulation on TC-related features.

For the Strong-N type, composite anomalies of 3060-day and 3-10-day modes for S850 on day -2 (two days before day 0 ) and day 0 and $\mathrm{V} 10$ and $\nabla \cdot \mathbf{V}_{\mathrm{Q}}$ on day 0 are shown in Fig. 8. TC positions on day -2 and day 0 are superimposed on S850 anomalies. From day -2 to day 0, 3-10-day S850 anomalies exhibit a cyclonic anomaly moving from the northern Philippines (Fig. 8a) northwestward toward the northern SCS to the southwest of Taiwan (Fig. 8b). TCs are located around the central region of this cyclonic anomaly, indicating the strong influence of TC activity on 3-10-day anomalies. Composite 3-10-day V10 anomalies (Fig. 8c) reveal that the cyclonic anomaly merges with anomalous northeasterly flows in its northern sector around Taiwan. This results in strong moisture flux convergence extending from the anomalous cyclonic center northeastward across Taiwan toward the oceans on its northeastern side (Fig. 8d). Note that Taiwan is divided by the CMRs into the western and eastern sections (see Fig. 2). The anomalous northeasterly flows encounter the CMRs to result in topographic lifting effect that in turn causes evident rainfall on the windward side over eastern Taiwan. Therefore, although the major center of the anomalous moisture flux convergence is located to the southwest of Taiwan, the topographic effect acts to cause more rainfall over eastern Taiwan than western Taiwan in company with enhanced northeasterly flows.

For the 30-60-day ISO, a zonal elongating cyclonic anomaly extends from the SCS into the WNP on day -2 (Fig. 8e). On day 0, the cyclonic anomaly over the SCS separates from that over the WNP to become an isolated 

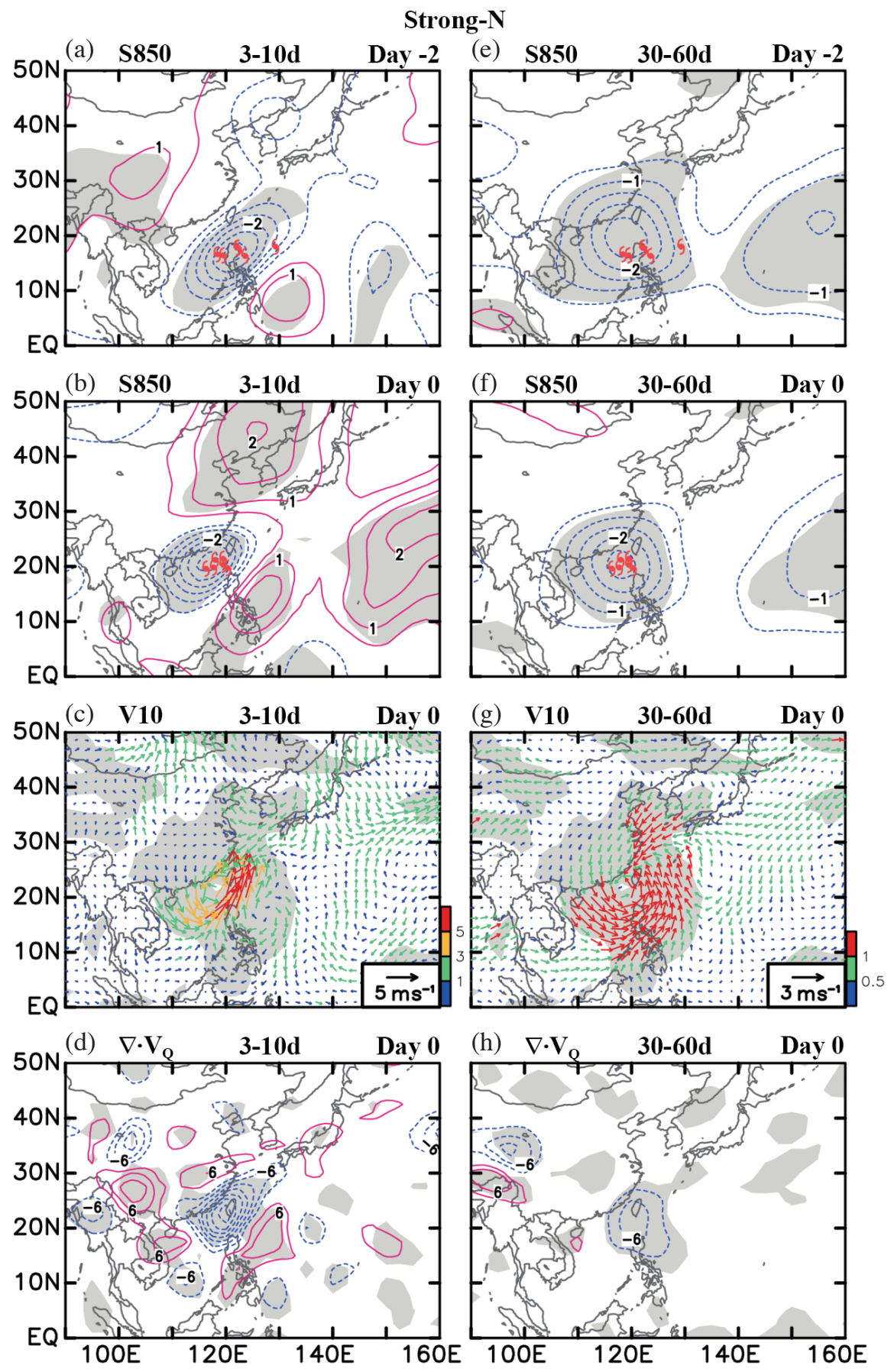

Fig. 8. Composite 3-10-day/30-60-day anomalies of the Strong-N type for (a)/(e) S850 on day -2, (b)/(f) S850 on day 0, (c)/(g) V10 on day 0, and (d)/(h) $\nabla \cdot V_{\mathrm{Q}}$ on day 0 . Contour intervals are $0.5 \times 10^{6} \mathrm{~m}^{2} \mathrm{~s}^{-1}$ for $\mathrm{S} 850$ anomalies and $3 \times 10^{5} \mathrm{~kg} \mathrm{~m}^{-1} \mathrm{~s}^{-1}$ for $\nabla \cdot \mathbf{V}_{\mathrm{Q}}$ anomalies. Composite anomalies significant at the 0.1 level of the Student- $t$ test are shaded. 
anomalous cyclone. TCs are located in the southern and eastern sectors of the cyclonic anomaly over the SCS on day -2 and move toward its center to the southwest of Taiwan on day 0 . This reflects that the cyclonic ISO anomaly provides favorable large-scale conditions for TCs moving toward its central region. Chen et al. (2019) analyzed ISO modulations on TC movement from the WNP into the SCS and showed two types of ISO modulating mechanisms. One type is that TCs are steered by anomalous easterly flows either to the south of an anomalous anticyclone or to the north of an anomalous cyclone. In this case, TCs have to locate in the boundary regions of the circulation anomalies to experience strong steering flows. For the other type, TCs are located in the middle region of an ISO cyclonic anomaly where steering flows are relatively weak. In this case, TCs move along with the cyclonic region of the 30-60-day anomaly from its southeastern/eastern sectors toward its central region. This modulating process is consistent with that shown in Fig. 8. Composite 30-60-day V10 anomalies (Fig. 8g) show that anomalous northeasterly flows merge with flows in the northern sector of the anomalous cyclone over the SCS to experience confluences in regions around northern Taiwan. A major convergence of moisture flux anomalies stretches from the anomalous cyclonic center northward toward Taiwan (Fig. 8h). A comparison of Figs. $8 \mathrm{c}$ and $\mathrm{g}$ discloses that flow confluences between the anomalous cyclone over the SCS and the anomalous northeasterly flows are weaker in the 30-60-day mode than in the 3-10-day mode. Consequently, anomalous moisture flux convergence is weaker in the former (Fig. 8h) than in the latter (Fig. 8d). The above analyses illustrate the different effects of ISO and 3-10-day modes for this TC type. The 3-10-day mode plays a major role in inducing moisture flux convergence and local rainfall on Taiwan, while ISO anomalies mainly modulate TC movement by providing favorable large-scale conditions for TCs to move forward (Chen et al. 2018b, 2020; Tan et al. 2019; Lai et al. 2021).

For the Weak-N type, TCs move closely with the center of a 3-10-day cyclonic anomaly from the Philippine Sea on day -2 (Fig. 9a) to the northern SCS on day 0 (Fig. 9b). On day 0, composite 3-10-day V10 anomalies show confluences between flows in the northern section of the anomalous cyclone centered over the SCS and anomalous northeasterly flows in the region to the northwest of Taiwan over eastern China around $30^{\circ} \mathrm{N}$ (Fig. 9c). The resultant 3-10day $\nabla \cdot V_{\mathrm{Q}}$ anomalies (Fig. 9d) present anomalous moisture flux convergence to the west of Taiwan extending from the northern SCS northward toward southeastern China. Composite evolutions of 30-60-day S850 anomalies show that TCs are within a zonal extending cyclonic anomaly across the SCS and the tropical WNP on day -2 (Fig. 9e) and move westward along this cyclonic anomaly toward its center over the SCS on day 0 (Fig. 9f). Composite 30-60-day V10 anomalies (Fig. 9g) demonstrate that there are no intensified anomalous northeasterly flows from the north to merge with surrounding flows of the weak anomalous cyclone over the SCS. Weak anomalies of moisture flux convergence only appear in the central region of the anomalous cyclone over the SCS, as revealed by composite $30-60$-day $\nabla \cdot V_{Q}$ anomalies (Fig. 9h).

For the Weak-S type, TCs move in a more southern region than those in the Strong-N and Weak-N types. Composite 3-10-day S850 anomalies from day -2 (Fig. 10a) to day 0 (Fig. 10b) show a cyclonic anomaly moving westward from the Philippine Sea toward the SCS along the $15^{\circ}-20^{\circ} \mathrm{N}$ zone. TC movement adheres to the anomalous cyclonic center. Composite 3-10-day V10 anomalies (Fig. 10c) show no evident anomalous northeasterly flows moving toward the SCS. This connects with the fact that TCs in the Weak-S type are located too far south to enhance both the meridional pressure gradient and northeasterly flows. Taiwan is mainly influenced by cyclonic flows of the anomalous cyclone in the SCS. Without noticeable flow confluences, anomalies of moisture flux convergence have a weak center in the SCS with a northeastward extension following the spatial distribution of the anomalous cyclone (Fig. 10d). Composite 30-60-day S850 anomalies present a weak cyclonic circulation south of $20^{\circ} \mathrm{N}$ across the SCS and WNP on day -2 (Fig. 10e) and day 0 (Fig. 10f). TCs move westward along this zonal anomalous cyclone from the WNP on day -2 into the cyclonic center over the SCS on day 0. Composite 3060-day V10 anomalies on day 0 (Fig. 10g) show weak cyclonic flows over the SCS and weak northeasterly flows to the northeast of Taiwan. These two anomalous flows do not have evident confluences in the vicinity of Taiwan. Weak cyclonic flows and no flow confluences result in no discernible patterns of 30-60-day $\nabla \cdot V_{\mathrm{Q}}$ anomalies around Taiwan (Fig. 10h). Rainfall in Taiwan is thus weakest among the three TC types.

To quantitatively measure the relative effects of the 3-10-day and 30-60-day modes on local rainfall in Taiwan, areal means of $\nabla \cdot \mathbf{V}_{\mathrm{Q}}$ anomalies on day 0 over the Taiwan region $\left(120^{\circ}-122.5^{\circ} \mathrm{E}, 22.5^{\circ}-25^{\circ} \mathrm{N}\right)$ for these two modes are shown in Table 2. For each of the three TC types, anomalous $\nabla \cdot \mathbf{V}_{\mathrm{Q}}$ value is much stronger in magnitude in the 3-10-day mode than the 30-60-day mode, indicating the dominant role of the 3-10-day mode in causing local rainfall in Taiwan. The areal-mean value of 30-60-day $\nabla \cdot \mathbf{V}_{\mathrm{Q}}$ anomaly for Strong-N type TCs has a stronger magnitude than the other two types. This magnitude is comparable to those of the 3-10-day anomalies for Weak-N and Weak-S types. This suggests that the 30-60-day mode makes noticeable contributions to local rainfall over Taiwan in the Strong-N type. This is coherent with the results that the 3060-day cyclonic anomaly centered in the SCS has a stronger intensity in the Strong-N type than the other two types. Stronger cyclonic anomalies result in stronger anomalies of confluences and moisture flux convergence to enhance local 
Weak-N
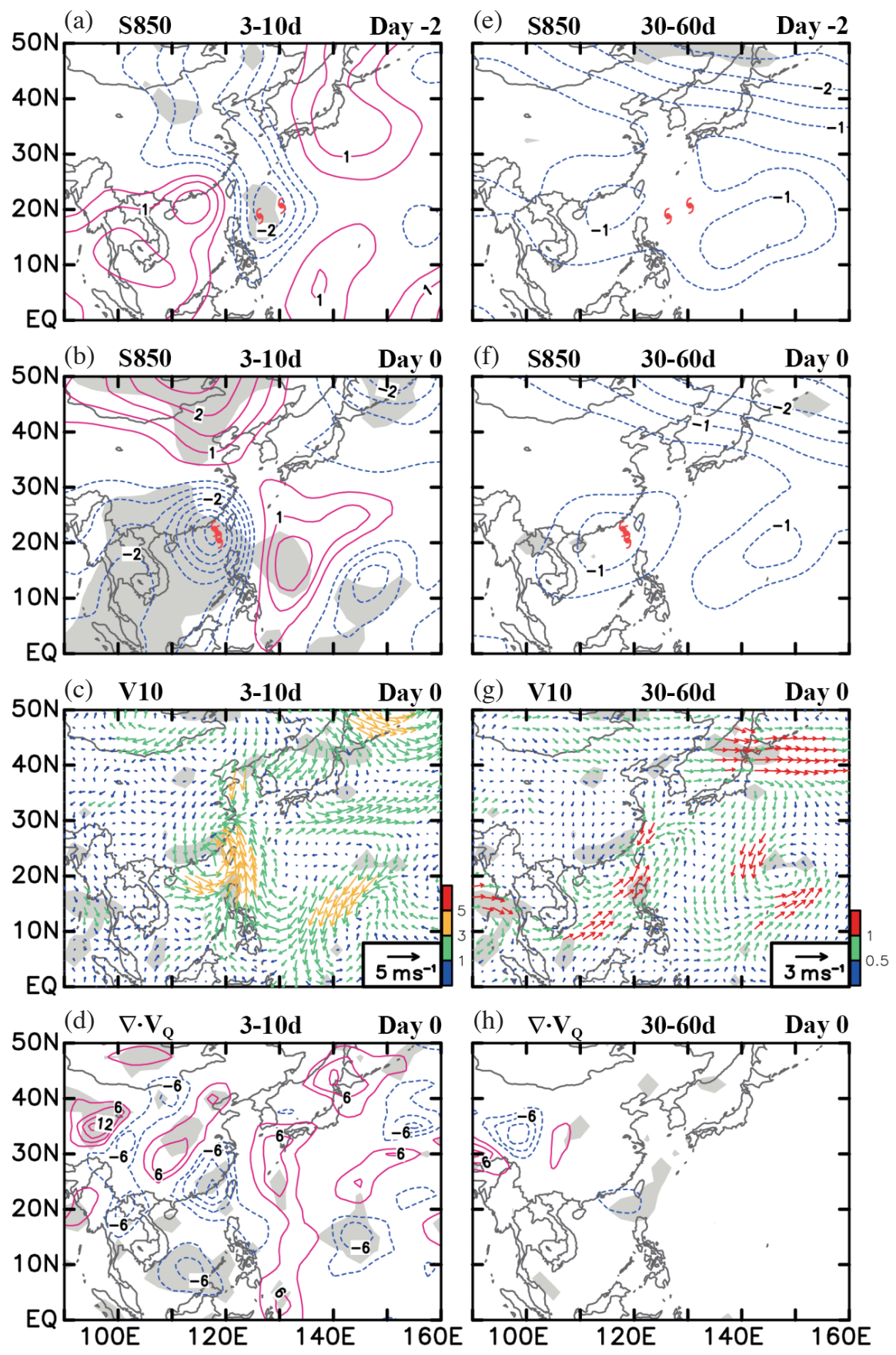

Fig. 9. As in Fig. 8, except for the Weak-N type. 


\section{Weak-S}
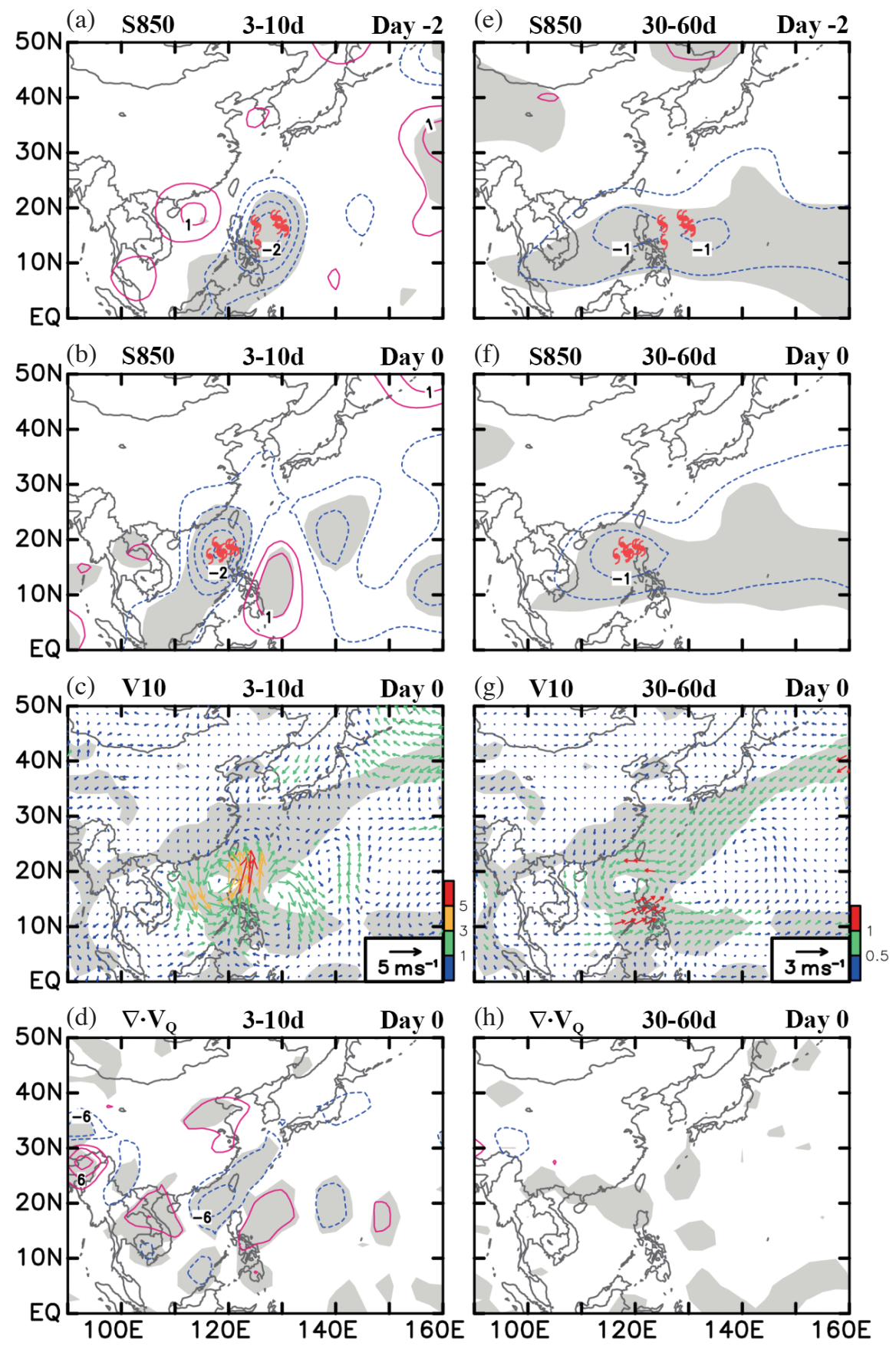

Fig. 10. As in Fig. 8, except for the Weak-S type. 
rainfall over Taiwan by the 30-60-day mode. For the 3-10day mode, TCs move along with the center of the anomalous cyclone from the WNP into the SCS. This cyclonic anomaly is stronger in intensity in Strong- $\mathrm{N}$ and Weak-N types than the Weak-S type. The appearance of a strong cyclonic anomaly in the SCS acts to enhance the meridional pressure gradient that in turn intensifies northeasterly flows. Flows over the northern sector of the cyclonic anomaly merge with anomalous northeasterly flows in the region overlying Taiwan in the Strong- $\mathrm{N}$ type, but to the west of Taiwan in the Weak-N type, resulting in stronger rainfall in Taiwan in the former type and weak rainfall in the latter type. The weak cyclonic anomaly in the Weak-S type does not induce evident anomalous northeasterly flows, yielding indiscernible moisture flux convergence and weak rainfall in Taiwan. For all TC types, processes of rainfall modulation induced by the 3-10-day mode largely resemble those imposed by the real-time mode. Overall, the 3-10-day mode dominates over the 30-60-day mode in determining rainfall variability over Taiwan. The major effect of the 30-60-day mode is to guide TC movement in all TC types.

\section{CONCLUSIONS}

During October, Taiwan is affected by the northeast monsoon and TC activity. These two features exhibit a peculiar interaction modulating rainfall over Taiwan. When a TC moves through the Western Pacific warm pool to the south and southwest of Taiwan, its low-pressure system may enhance northeasterly monsoonal flows via an intensification of the meridional pressure gradient between them. Strengthened flows from the north move toward the windward side on eastern Taiwan by which rainfall over this region is modulated. The main purpose of this study is to investigate rainfall variability in Taiwan during October modulated by TC-northeasterly flow interactions for different TC types. The relative role of the 30-60-day ISO in the modulation of local rainfall in Taiwan is also examined.

For TC warning periods issued by the CWB of Taiwan, the day with maximum daily rainfall at Ilan over northeastern Taiwan is defined as day 0. At 0600 UTC of day 0 , if a $\mathrm{TC}$ is positioned north (south) of $19^{\circ} \mathrm{N}$ in the $115^{\circ}-122^{\circ} \mathrm{E}$ region, it is categorized as a northern (southern) track. TCs providing maximum daily rainfall at Ilan greater (smaller) than $100 \mathrm{~mm}$ are sorted as strong (weak) rainfall types. The above categorizations result in six TCs with strong rainfall and northern tracks (Strong-N), three TCs with weak rainfall and northern tracks (Weak-N), and eight TCs with weak rainfall and southern tracks (Weak-S). Composite means of rainfall over 10 major stations in Taiwan on day 0 reveal that rainfall is much greater over eastern Taiwan than western Taiwan. Rainfall over eastern Taiwan is strongest for Strong-N type TCs (183 - $265 \mathrm{~mm})$, followed by the Weak$\mathrm{N}$ type $(23-115 \mathrm{~mm})$. It is weakest for the Weak-S type (32
- $75 \mathrm{~mm}$ ). Large-scale circulations related to these three TC types exhibit a common feature. This feature is a meridional circulation pair consisting of a northern high and a southern low embedding Taiwan. The southern low connects TC activity with its center to a more northern region over the SCS for Strong-N and Weak-N types and to a more southern region for the Weak-S type. The meridional pressure gradient between the circulation pair is thus stronger in Strong-N and Weak-N types than the Weak-S type. Meanwhile, frontogenesis near the northeast coast of Taiwan generally occurs in TC cases of the Strong-N type. Flows of the southern low merge with intensified northeasterly flows in regions around Taiwan for the Strong-N type, to the west of Taiwan for the Weak-S type, and to the south of Taiwan over the SCS for the Weak-S type. Following patterns of flow confluences, moisture flux convergence has its strongest (weakest) intensity over Taiwan, leading to strongest (weakest) rainfall over eastern Taiwan in the Strong-N (Weak-S) type. Analysis results indicate that during October, the influence of large-scale circulations on local rainfall over eastern Taiwan is highly related to TC track features and subsequent TC-northeast flow interactions.

The relative role of the 30-60-day ISO in the modulation of local rainfall over Taiwan is compared with that of the 3-10-day transient mode. For the transient mode, TCs in all three TC types move closely with the center of a 3-10-day anomalous cyclone propagating westward from the tropical WNP toward the northern SCS. Major patterns and the intensity of flow confluences and moisture flux convergence of the 3-10-day mode resemble well those of the real time mode. For the 30-60-day ISO mode, its major effect is to provide a favorable condition of a zonal extending anomalous cyclone to guide TCs westward from the tropical WNP toward its central region over the northern SCS. Contributions of ISO anomalies to moisture flux convergence over Taiwan are weaker than those by the 3-10-day mode. Overall, the 3-10-day mode plays a dominant role in determining local rainfall variability over Taiwan in these TC types, while the major effect of ISO anomalies is to steer TC movement along the oceans to the south and southwest of Taiwan.

Our analyses demonstrate the existence of TC-northeast monsoon interactions enhancing rainfall over eastern Taiwan during October. This is induced by a TC's remote effect intensifying the meridional pressure gradient and flow confluences between a TC to the south of Taiwan and northeasterly flows north of Taiwan. The intensified pressure gradient results in enhanced entrance of northeasterly flows onto Taiwan, impinging on the north-southerly distributed CMRs. Effects of topographic lifting and flow confluence enhance local moisture flux convergence on the windward side of the CMRs, providing favorable conditions for heavy rainfall over northeastern and eastern Taiwan. This type of remote interaction is more evident for TCs with a more northern track than a more southern track. ISO anomalies 
play a minor role in modulating rainfall variability in these TC types. The relative role of ISO is different form that found in the southwest monsoon season. During summer, an anomalous 30-60-day cyclone may propagate northward or northwestward to a position north of Taiwan. Anomalous westerly flows over its southern sector merge with prevailing southwesterly flows to provide persistent moisture supply for prolonged heavy rainfall over southern Taiwan during landfall and subsequent days (Chen and Shih 2012; Chen et al. 2013). ISO anomalies play a more important role in determining TC-monsoonal flow interactions and local rainfall variability in Taiwan during summer than they do in October. Results of this study will help us better understand interactions between TCs and the monsoonal system which may improve predictions of TC-induced rainfall over Taiwan and the surrounding regions.

Acknowledgements The authors thank anonymous reviewers for their valuable comments that helped improve the scientific content of this paper. This study was supported by the Ministry of Science and Technology, Taiwan, under grants MOST 108-2111-M-992-001-MY3, MOST 109-2811-M-992-500, and MOST 109-2111-M-002-004.

\section{REFERENCES}

Aiyyer, A., A. Mekonnen, and C. J. Schreck, 2012: Projection of tropical cyclones on wavenumber-frequencyfiltered equatorial waves. J. Clim., 25, 3653-3658, doi: 10.1175/JCLI-D-11-00451.1. [Link]

Chan, J. C. L., 2000: Tropical cyclone activity over the western North Pacific associated with El Niño and La Niña events. J. Clim., 13, 2960-2972, doi: 10.1175/1520-0442(2000)013<2960:TCAOTW>2.0. $\mathrm{CO} ; 2$. [Link]

Chen, J.-M. and H.-S. Chen, 2011: Interdecadal variability of summer rainfall in Taiwan associated with tropical cyclones and monsoon. J. Clim., 24, 5786-5798, doi: 10.1175/2011 JCLI4043.1. [Link]

Chen, J.-M. and C.-F. Shih, 2012: Association between northward-moving tropical cyclones and southwesterly flows modulated by intraseasonal oscillation. J. Clim., 25, 5072-5087, doi: 10.1175/JCLI-D-11-00264.1. [Link]

Chen, J.-M., F.-C. Lu, S.-L. Kuo, and C.-F. Shih, 2005: Summer climate variability in Taiwan and associated large-scale processes. J. Meteorol. Soc. Jpn., 83, 499516, doi: $10.2151 /$ jmsj.83.499. [Link]

Chen, J.-M., J.-L. Chu, C.-F. Shih, and Y.-C. Tung, 2010a: Interannual variability of circulation-rainfall relationship in Taiwan during the Mei-yu season. Int. J. Climatol., 30, 2264-2276, doi: 10.1002/joc.2049. [Link]

Chen, J.-M., T. Li, and C.-F. Shih, 2010b: Tropical cycloneand monsoon-induced rainfall variability in Taiwan. $J$. Clim., 23, 4107-4120, doi: 10.1175/2010JCLI3355.1.
[Link]

Chen, J.-M., P.-H. Tan, and C.-F. Shih, 2013: Heavy Rainfall Induced by Tropical Cyclones across Northern Taiwan and Associated Intraseasonal Oscillation Modulation. J. Clim., 26, 7992-8007, doi: 10.1175/JCLID-12-00692.1. [Link]

Chen, J.-M., P.-H. Tan, L. Wu, J.-S. Liu, and H.-S. Chen, 2017: Climatological analysis of passage-type tropical cyclones from the western North Pacific into the South China Sea. Terr. Atmos. Ocean. Sci., 28, 327-343, doi: 10.3319/TAO.2016.10.04.02. [Link]

Chen, J.-M., C.-H. Wu, P.-H. Chung, and C.-H. Sui, 2018a: Influence of intraseasonal-interannual oscillations on tropical cyclone genesis in the western North Pacific. J. Clim., 31, 4949-4961, doi: 10.1175/JCLID-17-0601.1. [Link]

Chen, J.-M., P.-H. Tan, L. Wu, H.-S. Chen, J.-S. Liu, and C.-F. Shih, 2018b: Interannual variability of summer tropical cyclone rainfall in the western North Pacific depicted by CFSR and associated large-scale processes and ISO modulations. J. Clim., 31, 1771-1787, doi: 10.1175/JCLI-D-16-0805.1. [Link]

Chen, J.-M., C.-H. Wu, J. Gao, P.-H. Chung, and C.-H. Sui, 2019: Migratory Tropical Cyclones in the South China Sea Modulated by Intraseasonal Oscillations and Climatological Circulations. J. Clim., 32, 6445-6466, doi: 10.1175/JCLI-D-18-0824.1. [Link]

Chen, J.-M., P.-H. Lin, C.-H. Wu, and C.-H. Sui, 2020: Track variability of South China Sea-formed tropical cyclones modulated by seasonal and intraseasonal circulations. Terr. Atmos. Ocean. Sci., 31, 239-259, doi: 10.3319/TAO.2019.11.07.02. [Link]

Chen, T.-C. and C.-C. Wu, 2016: The remote effect of Typhoon Megi (2010) on the heavy rainfall over northeastern Taiwan. Mon. Weather Rev., 144, 3109-3131, doi: 10.1175/MWR-D-15-0269.1. [Link]

Chen, T.-C., S.-Y. Wang, and M.-C. Yen, 2006: Interannual variation of the tropical cyclone activity over the western North Pacific. J. Clim., 19, 5709-5720, doi: 10.1175/JCLI3934.1. [Link]

Chen, T.-C., S.-Y. Wang, M.-C. Yen, and A. J. Clark, 2009: Impact of the intraseasonal variability of the western North Pacific large-scale circulation on tropical cyclone tracks. Weather Forecast., 24, 646-666, doi: 10.1175/2008WAF2222186.1. [Link]

Duchon, C. E., 1979: Lanczos filtering in one and two dimensions. J.Appl. Meteorol.Climatol., 18, 1016-1022, doi: 10.1175/1520-0450(1979)018<1016:LFIOAT >2 . $0 . \mathrm{CO} ; 2$. [Link]

Harr, P. A. and R. L. Elsberry, 1991: Tropical cyclone track characteristics as a function of large-scale circulation anomalies. Mon. Weather Rev., 119, 1448-1468, doi: 10.1175/1520-0493(1991)119<1448:TCTCAA>2.0. CO;2. [Link] 
Hong, C.-C., M.-Y. Lee, H.-H. Hsu, and J.-L. Kuo, 2010: Role of submonthly disturbance and 40-50 day ISO on the extreme rainfall event associated with typhoon Morakot (2009) in southern Taiwan. Geophys. Res. Lett., 37, L08805, doi: 10.1029/2010GL042761. [Link]

Huang, C.-Y., C.-S. Wong, and T.-C. Yeh, 2011: Extreme rainfall mechanisms exhibited by typhoon Morakot (2009). Terr. Atmos. Ocean. Sci., 22, 613-632, doi: 10.3319/TAO.2011.07.01.01(TM). [Link]

Kalnay, E., M. Kanamitsu, R. Kistler, W. Collins, D. Deaven, L. Gandin, M. Iredell, S. Saha, G. White, J. Woollen, Y. Zhu, M. Chelliah, W. Ebisuzaki, W. Higgins, J. Janowiak, K. C. Mo, C. Ropelewski, J. Wang, A. Leetmaa, R. Reynolds, R. Jenne, and D. Joseph, 1996: The NCEP/NCAR 40-year reanalysis project. Bull. Amer. Meteorol. Soc., 77, 437-472, doi: 10.1175/1520-0477(1996)077<0437:TNYRP>2.0. CO;2. [Link]

Kim, J.-H., C.-H. Ho, H.-S. Kim, C.-H. Sui, and S. K. Park, 2008: Systematic variation of summertime tropical cyclone activity in the western North Pacific in relation to the Madden-Julian oscillation. J. Clim., 21, 11711191, doi: 10.1175/2007JCLI1493.1. [Link]

Klotzbach,P. J., 2014: The Madden-Julian Oscillation's impacts on worldwide tropical cyclone activity. J. Clim., 27, 2317-2330, doi: 10.1175/JCLI-D-13-00483.1. [Link]

Kubota, H. and B. Wang, 2009: How much do tropical cyclones affect seasonal and interannual rainfall variability over the western North Pacific? J. Clim., 22, 54955510, doi: 10.1175/2009JCLI2646.1. [Link]

Lai, T.-L., J.-M. Chen, C.-H. Sui, P.-H. Tan, L. Wu, and M.Y. Tsai, 2021: Interannual variability of summer tropical cyclone activity in the northwestern North Pacific modulated by El Niño-Southern Oscillation and intraseasonal oscillation. Int. J. Climatol., 41, 6283-6299, doi: 10.1002/joc.7194. [Link]

Lander, M. A., 1996: Specific tropical cyclone track types and unusual tropical cyclone motions associated with a reverse-oriented monsoon trough in the western North Pacific. Weather Forecast., 11, 170-186, doi: 10.1175/1520-0434(1996)011<0170: STCTTA>2.0. CO;2. [Link]

Li, R. C. Y. and W. Zhou, 2013: Modulation of western North Pacific tropical cyclone activity by the ISO. Part
I: Genesis and intensity. J. Clim., 26, 2904-2918, doi: 10.1175/JCLI-D-12-00210.1. [Link]

Li, R. C. Y., W. Zhou, J. C. L. Chan, and P. Huang, 2012: Asymmetric modulation of western North Pacific cyclogenesis by the Madden-Julian oscillation under ENSO conditions. J. Clim., 25, 5374-5385, doi: 10.1175/JCLI-D-11-00337.1. [Link]

Lin, Y.-H. and C.-C. Wu, 2021: Remote rainfall of Typhoon Khanun (2017): Monsoon mode and topographic mode. Mon. Weather Rev., 149, 733-752, doi: 10.1175/ MWR-D-20-0037.1. [Link]

Lu, R., 2001: Interannual variability of the summertime North Pacific subtropical high and its relation to atmospheric convection over the warm pool. J. Meteorol. Soc. Jpn., 79, 771-783, doi: 10.2151/jmsj.79.771. [Link]

Lu, R. and B. Dong, 2001: Westward extension of North Pacific subtropical high in summer. J. Meteorol. Soc. Jpn., 79, 1229-1241, doi: 10.2151/jmsj.79.1229. [Link]

Su, S.-H., H.-C. Kuo, L.-H. Hsu, and Y.-T. Yang, 2012: Temporal and spatial characteristics of typhoon extreme rainfall in Taiwan. J. Meteorol. Soc. Jpn., 90, 721-736, doi: 10.2151/jmsj.2012-510. [Link]

Tan, P.-H., J.-Y. Tu, L. Wu, H.-S. Chen, and J.-M. Chen, 2019: Asymmetric relationships between El NiñoSouthern Oscillation and entrance tropical cyclones in the South China Sea during fall. Int. J. Climatol., 39, 1872-1888, doi: 10.1002/joc.5921. [Link]

Tu, J.-Y. and J.-M. Chen, 2019: Large-scale indices for assessing typhoon activity around Taiwan. Int. J. Climatol., 39, 921-933, doi: 10.1002/joc.5852. [Link]

Tu, J.-Y. and C. Chou, 2013: Changes in precipitation frequency and intensity in the vicinity of Taiwan: Typhoon versus non-typhoon events. Environ. Res. Lett., 8,014023, doi: 10.1088/1748-9326/8/1/014023. [Link]

Wang, B. and J. C. L. Chan, 2002: How strong ENSO events affect tropical storm activity over the western North Pacific. J. Clim., 15, 1643-1658, doi: 10.1175/1520-0442(2002)015<1643:HSEEAT>2.0. CO;2. [Link]

Wu, L., Z. Wen, R. Huang, and R. Wu, 2012: Possible linkage between the monsoon trough variability and the tropical cyclone activity over the western North Pacific. Mon. Weather Rev., 140, 140-150, doi: 10.1175/MWR-D-11-00078.1. [Link] 